\title{
Enrichment plantings as a means of enhanced bush food and bush medicine plant production in remote arid regions - a review and status report
}

\begin{tabular}{c|c} 
L.S. Lee & Kim Courtenay \\
$\begin{array}{c}\text { CRC for Remote Economic Participation \& } \\
\text { Southern Cross University } \\
\text { slade.lee@scu.edu.au }\end{array}$ & Kimberley Training Institute \\
\hline
\end{tabular}

Keywords: enrichment planting; savannah enrichment; bush food; bush medicine; Terminalia ferdinandiana; Solanum centrale

\begin{abstract}
Attempts to establish horticultural businesses in remote Aboriginal and Torres Strait Islander communities have seldom experienced sustained success. Various reasons have been proposed - inadequate technical and business expertise, insufficient planning and consultation, limited local demand for products and long distances to external markets, harsh seasonal conditions adverse to farming, limited irrigation water availability, competing community interests, and the laborious nature of the work under arduous conditions. This paper proposes a further reason and explores a new approach as an alternative to horticulture. Enrichment planting is a strategy involving the establishment of plants for food, medicine or other uses, in a landscape that is otherwise natural and largely undisturbed. The establishment of enrichment plantings of bush food and medicinal plants in bushland settings complements wild harvest, and yet as an alternative to the agricultural farming approach, it accommodates the important social and cultural interactions of value to Aboriginal people in collecting bush food and traditional medicines, while also generating a source of income. Through a review of the limited published information available and documentation of the current status in Australia, the use of enrichment planting is examined in the global context and its application to bush food and traditional medicine production for remote Aboriginal communities is explored.
\end{abstract}

\section{Introduction}

As will be detailed, the use of enrichment plantings as a means of bush food and traditional medicine production in remote Australian Aboriginal and Torres Strait Islander communities has limited application. Enrichment plantings involve establishment of relatively high densities of propagated plants in a largely undisturbed, seemingly wild situation to supplement the existing native plants. To the casual observer, the planting appears the same as any other bush-scape. But the benefit, from a plant product enterprise vantage, is the natural biodiversity of the planted area is maintained while plants can be minimally managed to ensure a satisfactory yield of crop. Harvesting may be conducted in a way akin to the traditional wild harvesting practice of Aboriginal people, but more efficiently and reliably because of the increased density of the desired plants. The enrichment planting business therefore mimics traditional wild harvesting practice of Aboriginal people and is thus culturally relevant, yet it is more consistent, more productive and more labour-efficient; less travel is required between sites and between plants, the site can be readily monitored and treated for weeds, pests and disease incursions, and plants may be tended to promote ideal growth. In addition to the business opportunity, the 
harvest practice can encourage intergenerational transfer of Traditional Knowledge (alternatively termed Indigenous Ecological Knowledge) and play an important role in social and cultural interaction among community members. Enrichment planting also provides the opportunity for high value bush food to be grown in close proximity to Aboriginal communities, making management and harvesting more practicable. Aboriginal unemployment is a significant problem (Gray, Hunter \& Lohoar, 2012) and is not improving (Productivity Commission, 2015). The adoption of enrichment plantings could present a pathway to employment in culturally relevant pursuits and an opportunity for Aboriginal and Torres Strait Islander people to develop businesses, particularly in remote regions.

The prospect of Aboriginal people growing bush foods and traditional medicines for commercial gain in a culturally relevant manner by enrichment planting has been proposed for arid regions of Australia (Fawcett, 2011; Merne Altyerre-ipenhe Reference Group, Douglas \& Walsh, 2011; Walsh \& Douglas, 2011; RIRDC, 2014). The plant species involved are as diverse as Kakadu Plum (Terminalia ferdinandiana) (Cunningham, Garnett \& Gorman, 2009a; Cunningham, Garnet, Gorman, Courtenay \& Boehme 2009b) and bush tomato (Solanum centrale) (Ninti One Ltd, 2015). Enrichment planting has been conducted for some years with Kakadu Plum in the Kimberley (National Institute of Complementary Medicine, 2009; Rola-Rubzen, Gibbs, Gabunada, Altangerel, Fung, Rubzen \& Carter, 2011) - refer to Figure 1. The practice has also been proposed for Aboriginal communities in the wet tropics (Bristow, Annandale \& Bragg, 2003). However, the approach has not become widespread to date and the only known established application is with Kakadu Plum (Gubinge in Nyul Nyul language) near Broome in Western Australia (Torres, 2010; Pat Torres, Mayi Harvests, pers. comm.).

Published information on enrichment planting practices globally is limited and its application in the Australia context is only just beginning. This paper serves to review such relevant information as is available and to report on the current status of this approach to bush food and medicine production.

Figure 1: Distribution of Terminalia ferdinandiana and Solanum centrale

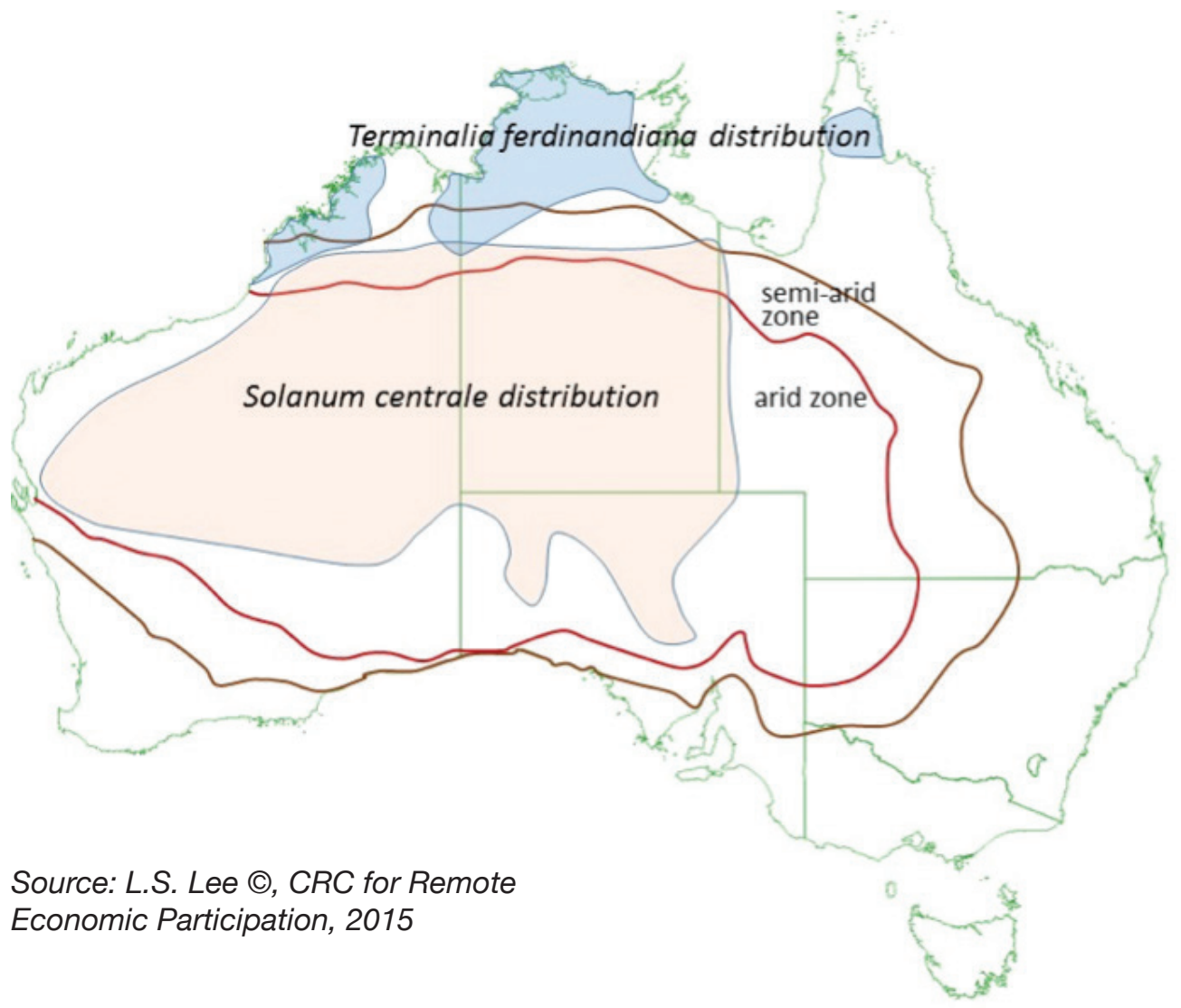




\section{Enrichment planting}

Enrichment planting has been practiced for thousands of years in agrarian traditional cultures as diverse as in Africa (Campbell, Clarke \& Gumbo, 1991), Central and South America (Ladio \& Lozada, 2009; Eyssartier, Ladio \& Lozada, 2011; Suarez, Williams-Linera, Trejo, Valdez-Hernandez, Cetina-Alcala \& Vibrans, 2012), Asia (Joshi, Wijaya, Sirait \& Mulyoutami, 2004), the Pacific (Clarke \& Thaman, 1997) and many other regions of the world (Bharucha \& Pretty, 2010). The practice has also been traditionally applied to some extent in non-agrarian cultures of most continents (Berkes, Colding \& Folke, 2000; Bharucha \& Pretty, 2010; Barlow, Gardner, Lees, Parry \& Peres, 2012). Moreover, enrichment planting has proven to be an effective approach to food security and supporting livelihoods in arid zones in various parts of the world (Harris \& Hillman, 1989; Barrow \& Mlenge, 2003; Ladio \& Lozada, 2009; Reij, 2010; Suarez et al., 2012).

A White Paper is a major policy document prepared by the Australia Government and released publicly. It outlines the policy settings and approach in a particular area of interest. In a submission to the White Paper on the Competitiveness of the Agriculture Sector, the Rural Industries Research and Development Corporation (RIRDC) points out, in regard to bush food and medicinal enterprises in Australia:

Some of these industries have the potential to be developed in remote Indigenous communities, using enrichment planting methodologies consistent with important social and environmental co-benefits. (RIRDC, 2014, p. 8)

Undertaking activities of food and medicine production is primarily a utilitarian pursuit from the perspective of Western culture; but from an Australian Aboriginal outlook such activities carry much more complex and nuanced values, embracing spiritual, cultural, knowledge-transfer and social elements (Merne Altyerre-ipenhe Reference Group et al., 2011; Walsh, Dobson \& Douglas, 2013). On the other hand, having a predominantly traditional hunter-gatherer heritage, it may be appreciated that there is little if any relevance to the cultural interests of Aboriginal people in agrarian practices. It may be argued that a disconnect between horticultural practice and a hunter-gatherer lifestyle could be partly responsible for the limited sustained success in adoption of farming by Aboriginal people in remote regions where traditional culture plays a significant role in daily lives (ACIAR, 2007, p. 7; Denham, Donohue \& Booth, 2009).

It is significant to note, however, there is evidence of rudimentary development of horticulture in far northern Australia in the distant past (Denham et al., 2009) and it seems possible that some type of 'pre-agricultural' enrichment planting may have been formerly practiced by Aboriginal people (Hynes \& Chase, 1982; Chase, 1989). Moreover, Chase (1989) explains the complex societal relationships that necessarily underpin such practices, which were based on what Chase (1989) defined as:

...small-group localisation, long-term coastal occupation, and a complex Aboriginal science of speciation, plant behaviour, and extractive technologies. (p. 43)

The result was a series of what Hynes \& Chase (1982) call "domuses", amongst which clan groups would circulate; and the tending of useful plants at these locations, that the authors refer to as "domiculture" (Hynes \& Chase, 1982; Chase, 1989). According to those researchers, far from being a semi-random nomadic pursuit, this they claim, was a highly organised function governed by customary law and traditional knowledge that ensured 'spiritual safety of routine action' (Chase, 1989). Cosgrove (1996) suggests, however, that the practice may have been be somewhat less structured. 
This little-recognised isolated proto-agricultural circumstance notwithstanding, the fact preEuropean Aboriginal societies lived a hunter-gather subsistence (Yen, 1989) and that nowhere did they develop a system of land-clearing for crop production (Chase, 1989), the tenet of agrarian practice lacking cultural relevance to Aboriginal traditional perspectives remains valid.

Whereas the predominant thrust of enrichment planting globally is for reafforestation of disturbed landscapes, rather than food or medicine production (Ganz \& Durst, 2003), numerous reports point also to the long-term carbon storage benefits of enrichment plantings of perennial plants (see Albrecht and Kandji (2003), Oelbermann, Voroney and Gordon (2004), Keefe, Alavalapati and Pinheiro (2012), and Hill, Pert, Davies, Robinson, Walsh and FalcoMammone (2013)), and includes abatement applications in arid environments (Takimoto, Nair \& Nair, 2008). Another significant interest in enrichment planting is for urban landscape enhancement, where there are benefits in food security, livelihood strategies, conservation of useful plants, redressing ecosystem degradation, and biodiversity conservation (Martini, Roshetko, van Noordwijk, Rahmanulloh, Mulyoutami, Joshi \& Budidarsono, 2012; Cousins \& Witkowski, 2015). Although similar benefits no doubt could accrue to Indigenous communities in remote regions of numerous countries, that application has gone largely undocumented. The majority of activity in research, development and assessment of enrichment planting in association with traditional cultures occurs in the field of agroforestry (Schulze, Leighton \& Peart, 1994; Clarke \& Thaman, 1997; Keefe et al. 2012; Suarez et al., 2012; Martini et al. 2012).

Participation in forest management activities, including the practice of enrichment planting, taps into a range of cultural interests and thereby presents an opportunity for Aboriginal and Torres Strait Islander communities (Commonwealth of Australia, 2004). Local traditional knowledge of plants has proven invaluable in guiding and managing enrichment plantings in various countries (Schulze et al., 1994; Clarke \& Thaman, 1997; Berkes et al., 2000; Bharucha \& Pretty, 2010; Suarez et al., 2012). The potential of traditional knowledge for development of similar initiatives in Australia is recognised (RIRDC, 2014). Loss of traditional knowledge about plants and their uses is therefore a concern in Australia (Walsh \& Douglas, 2011) and in other cultures (Clarke \& Thaman, 1997; Ladio \& Lozada, 2009; Eyssartier et al., 2011).

With the exception of work in the Kimberley region (Courtenay, 2009) there has been very little systematic investigation of enrichment planting for bush food and traditional medicines in remote Australia. While limited developmental work has been conducted and valuable observations recorded, no methodical research has yet been conducted. The technical and environmental risks seem small, although Cunningham et al. (2009b) do indicate the concern for potential genetic contamination of local gene pools that could result through the introduction of genotypes from other locales. This, however, is arguably a lesser risk than the introduction of invasive foreign species via enrichment plantings in agroforestry projects as has occurred in other countries (Baguinon, Quimado \& Francisco, 2005). The potential benefits seem apparent, in terms of micro-enterprise development as well as social and cultural interaction and traditional knowledge transfer, and the possibility that enrichment plantings may provide useful and culturally relevant options for financial independence to Aboriginal and Torres Strait Islander communities in remote Australia. The current and emerging status of this approach is discussed below.

\section{Savannah enrichment in north-western Australia and the Top End}

In investigating the enrichment planting concept for the cultivation of Terminalia ferdinandiana on Aboriginal communities in the Kimberley, the Kimberley Training Institute (KTI), formerly Kimberley College of TAFE, has developed an approach that combines traditional burning practices with modern horticultural techniques termed 'Savannah Enrichment'. KTI began 
incorporating the cultivation of the prized local bush fruit $T$. ferdinandiana (Gubinge / Kakadu Plum) into horticultural training programs on local Aboriginal communities in the mid-1990s as part of the Institute's commitment to supporting appropriate strategies for remote community development.

In 2004, following widening recognition of the fruit's exceptional nutritional qualities, a "gubinge rush" hit Broome when Sydney based company, Coradji Pty Ltd, offered pickers up to $\$ 20$ per kilogram for wild harvested fruit. While the opportunity for a new industry with benefits for local Aboriginal people was largely welcomed, there was controversy and concerns about the sustainability of large scale wild harvesting when trees long sourced by local people for fruit for their personal use were stripped and damaged by commercial pickers.

Cultivation was viewed by many then, as it is now, as a logical way to support the emerging industry. KTI saw the opportunity to assist by refining cultivation techniques through their Aboriginal training programs and over the next few years established plantations on three local Aboriginal communities through practical delivery. The plantations were drip irrigated and became well established in their first years demonstrating $T$. ferdinandiana could be cultivated on a commercial scale.

Recognised for its work in engaging Aboriginal and Torres Strait Islander communities while pioneering the cultivation of $T$. ferdinandiana, $\mathrm{KTI}$ built collaborative partnerships with various other agencies and organisations in promoting the advancement of the industry. In 2006, KTI was invited by the School of Environmental Studies at Charles Darwin University (CDU) in the Northern Territory (NT) to be a partner in an Australian Research Council (ARC) grant application to fund several PhD students to engage in research projects supporting the development of the industry.

The application was built around a philosophy of promoting an "Across the North" strategy for the industry linking the Kimberley and Top End of the NT to maximise involvement with and benefits for Aboriginal and Torres Strait Islander people and communities. In discussions on proposed cultivation methods it was agreed that to satisfy the market advantage of T. ferdinandiana as a natural wild product, conventional cultivation techniques on cleared land would not be as appropriate as a model that preserved natural biodiversity and fitted in with existing ecosystems. That funding application was unsuccessful but the philosophies endured.

A novel concept was born and the following year (2007) KTI undertook to investigate the initiative by establishing a training and research facility on a 20 hectare site at the Broome "12 Mile" in a partnership with the WA Department of Conservation and Land Management.

In establishing the site, $\mathrm{KTI}$ sought and received endorsement from the local Yawuru Traditional Owners who suggested the name Balu Buru, a Yawuru term meaning "place of trees". Over the following years trials were established through practical training in nationally accredited horticulture and land management Certificate courses. Student enrolments in the programs attracted a high percentage of Aboriginal people from across the Kimberley, including minimum security inmates from Broome Regional Prison. This engaged local people as key players in the emerging industry and taught them skills to be part of similar initiatives on their own communities in what has become known as "Savannah Enrichment".

Annually for each of the first five years, approximately a hectare of $T$. ferdinandiana was planted with around 200 trees. To assist the establishment of the planted seedlings, the irrigation systems employed in the Savannah Enrichment methodology were based on tried and proven techniques developed in the Middle East and now applied globally across arid regions. Preparation of each area involved hand removal of dead wood and slashing between the existing trees and perennial shrubs. By far the most dominant species was Acacia eriopoda or pindan wattle, which typical of the surrounding native savannah, comprised up to $90 \%$ of 
the woody vegetation and in some areas formed dense thickets. These dense acacia thickets, which can also include $A$. tumida, $A$. monticola and several other species, are a consequence of unmanaged fire regimes and consistent with large areas of the Kimberley and Top End of the NT since the end of Aboriginal "firestick farming" following European settlement.

The trials at Balu Buru provided valuable lessons in propagation techniques and in the effective establishment of $T$. ferdinandiana seedlings in the field but they also revealed a major challenge in controlling the prolific and resilient $A$. eriopoda. The area where the trials were planted contained a typically high percentage of the acacias. Because their life span is usually only about seven years, the strategy was to remove them when they died which would make way for the emerging T. ferdinandiana. However there was an enormous seed bank through the area and each Wet season (November - April) prolific numbers re-emerged. They were removed using hand tools but it was labour-intensive and not feasible on a large commercial scale. When the problem seemed insurmountable the solution came unexpectedly in 2012 .

In conjunction with the establishment of the trials, prescribed burning was carried out early each Dry season (May - October) as part of Conservation and Land Management training to create fire breaks around the planted area. After several years, it was revealed the successive cool burns effectively eliminated the $A$. eriopoda from the firebreak areas and created an open parkland effect. This was the same landscape described by Gammage (2011), which Aboriginal people had maintained across the savannah regions of the north through firestick farming. It indicated areas planned for enrichment planting could effectively have these acacia thickets and their seed banks removed with prescribed burning over several years prior to planting.

On a large scale, Savannah Enrichment could effectively reverse the cycle of expanding wildfire-tolerant plant communities and the coinciding loss of biodiverse woodlands and forests that has occurred across large areas of northern Australia since the end of traditional firestick farming. In a carbon economy, it could take the opportunities around savannah burning through the Carbon Farming Initiative to another level. Creating productive forests and woodlands using high-value, traditionally important native species thus presents multiple benefits.

From a human point of view, it engages people on remote communities, making use of existing infrastructure and presenting appealing, culturally relevant and healthy options for their economic future. Environmentally, it breaks the cycle of successive wildfires and presents a productive natural resource management system that can be applied across large areas of mismanaged country in Northern Australia. The combination of fire control and modern innovative techniques in horticulture has the capacity to transform a region that currently releases globally significant quantities of greenhouse gases through wildfires into a vast carbon sink.

The Savannah Enrichment concept is built around an understanding of the natural history of the Australian vegetation and landscape. In 1788, Aboriginal people occupied all corners of the country and firestick farming was a precise form of land management and an integral part of traditional culture. Anthropologists believe it was developed in response to the extinction of the megafauna and the habitats that sustained them, over 40,000 years ago. Firestick farming maintained the natural order for millennia but ended following European settlement and the displacement of Aboriginal people from their traditional lands. In the Kimberley and Top End of the NT, the end of firestick farming saw a marked increase in late Dry season wildfires with a negative impact on plant communities and natural biodiversity. Savannah enrichment reverses the effect of wildfires and recreates stable ecosystems built around long-lived forest and woodland tree species. 
The Savannah Enrichment innovation has evolved from KTI's commitment to supporting appropriate strategies for remote community development. Unlike training institutions in metropolitan areas, a significant percentage of KTl's clients are isolated and face limited employment opportunities. KTI's long term involvement with Traditional Aboriginal Elders and community leaders has built lasting relationships and fostered a 'walking together' philosophy. Savannah Enrichment has emerged from this commitment and these relationships as an innovative strategy that can contribute to the 'closing the gap' strategy of the Australian Government, which aims to reduce disadvantage in Indigenous communities. Far more than delivering training to service existing industries, KTI has demonstrated a commitment to recognising and implementing new initiatives with health, social, employment and environmental benefits and a capacity to preserve traditional culture.

Savannah Enrichment is a combination of individual elements recognised and authenticated by science and industry. Applied collectively as a methodology, it has been endorsed by a collaborative group of scientific and industry peers as appropriate and worthy of continued development. The potential to manipulate savannah plant communities through prescribed burning has been widely researched and documented (Whitehead, Purdon, Cooke, Russell-Smith \& Sutton, 2009; Edwards \& Allan, 2009), as has the effects of 'firestick farming' by Aboriginal people over millennia (Gammage, 2011).

As well as Terminalia ferdinandiana, KTI have investigated the cultivation of several other important bush foods as opportunities for remote communities. In the Savannah Enrichment model, these have included Terminalia cunninghamii (pindan walnut) and Buchanania obovata (wild mango).

At Bidyadanga community south of Broome, Ipomoea costata, a wild yam, and Solanum chippendalei, a bush tomato, have also been cultivated. In cultivating S. chippendalei, KTI worked closely with Yulparija Traditional Elder Merridoo Walbidi, and in 2007 assisted through a project at Kings Park Botanic Gardens and Parks Authority in Perth.

The Kings Park project investigated propagation techniques for solanums and discovered that soaking seeds in gibberellic acid resulted in germination rates allowing for the effective establishment of seedlings in a nursery environment (refer to Lee, 2012).

Through the Kings Park project, seedlings were provided to KTI and subsequently planted at Bidyadanga where several grew to maturity and produced fruit. The fruit, however, did not exhibit the same quality as wild fruit and Elders lost interest in the conventional cultivation approach. Subsequently there has been increasing interest in an approach where plants are established in a natural setting. Following discussions with Merridoo Walbidi there are plans to experiment with direct sowing of seed into sites prepared by burning, light working of the top soil, pre-treatment of seed (with gibberellic acid) and watering through the initial stages with in-line drip irrigation - i.e. enrichment planting.

\section{Ntaria initiative in central Australia}

Enrichment planting, by its very nature, is fundamentally suited to perennial plants - annual species require replanting each year, which necessitates agricultural practice. The Australian bush food plant Solanum centrale known as bush tomato and desert raisin (Lee, 2012) is a small herbaceous shrub yet is a perennial, like its close relative $S$. chippendalei. When damaged (e.g. by seasonal frost or fire) it regenerates vigorously from underground structures. The fruit of this plant is a food of traditional Aboriginal society of the Australian arid zone to which is it endemic occurring across a wide area (Lee, 2012). 
To ascertain whether establishment of enrichment plantings of $S$. centrale may benefit remote Aboriginal communities, and to determine what pitfalls may be encountered, a pilot project has begun at Ntaria (Hermannsburg) in Western Arrernte Country of central Australia. In addition to the planting procedure, community participants are receiving training in food safety and processing, business and marketing practices to assist them in developing local bush food micro-enterprises. These activities are designed to accommodate culturally relevant practices.

Two plots of undeveloped slightly undulating land of approximately one hectare were each planted with approximately 500 randomly distributed seedling plants - the sites were previously disturbed but had reverted to native plant growth. To aid establishment, plants were handwatered initially but subsequently receive minimal maintenance.

The plots were established shortly prior to the date of publication and it is anticipated that observations will be published in the future after the plantings have grown for several annual cycles.

\section{Conclusion}

Variants of enrichment planting approaches to ensuring adequate production of plant material for food, medicines and other traditional uses have been applied since before recorded history in almost every continent. Since the second half of the twentieth century, the method has been developed scientifically and used for a broader range of purposes incorporating forestry and conservation management. It has, however, had limited application in Australia, except for its use in reafforestation for the timber industry.

It has been recognised that participation by Aboriginal people from remote communities in enrichment planting projects may provide a beneficial source of food and plant-derived resources for local consumption, and to form the basis of Indigenous business enterprises. With an ancestral heritage of hunter-gatherer lifestyles, it may be argued that agricultural pursuits bear little relevance or interest to remote Aboriginal communities who are still significantly connected to their traditional customs and values. Enrichment planting approaches entail activities in a seemingly natural bush-scape setting, therefore they can provide opportunities for engagement in traditional practices and play a role in the transmission of traditional knowledge about gathering and processing food and medicine, ceremonies and lore involving particular plants, creation of traditional artefacts, and the like. Thus, proximity and density of desired plants in enrichment plantings offers a culturally relevant activity for Aboriginal people in remote places concurrently improving ease and efficiency of producing plant products and can underpin business initiatives. The encouraging instances of success in enrichment planting projects involving Aboriginal people, specifically those to date with Terminalia ferdinandiana, suggests this approach offers considerable promise of benefit for Aboriginal communities financially, socially and environmentally.

Projects with Terminalia ferdinandiana in northern Australia and Solanum centrale in central Australia and the north-west are forecast to continue, as prototypes for enrichment planting and to improve methodology. The approach is in its early stage of development, yet a small group of researchers is exploring other prospective species and associated traditional interests to which it would be applicable. This represents a potential opportunity for culturally relevant employment and business development in remote regions. 


\section{Acknowledgement}

The author Lee's research and development work with Australian bush tomato is undertaken with the financial support of the Australian Government Cooperative Research Centres Program through the Cooperative Research Centre for Remote Economic Participation (http://crc-rep.com/), and its parent organisation Ninti One Ltd (http://www.nintione.com.au/).

The work reported in this publication was supported by funding from the Australian Government Cooperative Research Centres Program through the Cooperative Research Centre for Remote Economic Participation (CRC-REP). The views expressed herein do not necessarily represent the views of the CRC REP or Ninti One Limited or its participants. Errors or omissions remain with the author. We also wish to acknowledge Ninti One for providing the resources to fund this Special Issue as well as the Northern Institute, at Charles Darwin University for providing the opportunity for publication.

\section{References}

ACIAR. (2007). Reconciliation Action Plan. Canberra, ACT: Australian Centre for International Agricultural Research. Retrieved from http://www.reconciliation.org.au/raphub/wp-content/uploads/raps/ federal/australian\%20centre\%20for\%20international\%20agricultural\%20research\%20rap.pdf.

Albrecht, A., \& Kandji, S.T. (2003). Carbon sequestration in tropical agroforestry systems. Agriculture, Ecosystems and Environment, 99, 15-27.

Baguinon, N.T., Quimado, M.O., \& Francisco, G.J. (2005). Country report on forest invasive species in the Philippines. In P. McKenzie, C. Brown, S. Jianghua and W. Jian (Eds.), The unwelcome guests. Proceedings of the Asia-Pacific Forest Invasive Species Conference (pp. 108-113). Kunming, China. Bangkok: FAO Regional Office for Asia and the Pacific.

Barlow, J. Gardner, T.A., Lees, A.C., Parry, L., \& Peres, C.A. (2012). How pristine are tropical forests? An ecological perspective on the pre-Columbian human footprint in Amazonia and implications for contemporary conservation. Biological Conservation, 151(1), 45-49.

Barrow, E., \& Mlenge, W. (2003). Trees as key to pastoralist risk management in semi-arid landscapes in Shinyanga, Tanzania and Turkana, Kenya. International Conference on Rural Livelihoods, Forests and Biodiversity. Bonn, Germany.

Berkes, F., Colding, J., \& Folke, C. (2000). Rediscovery of traditional ecological knowledge as adaptive management. Ecological Applications, 10(5), 1251-1262.

Bharucha, Z., \& Pretty, J. (2010). The roles and values of wild foods in agricultural systems. Philosophical Transactions of the Royal Society B, 365, 2913-2926.

Bristow, M., Annandale, M., \& Bragg, A. (2003). Introduction to tropical agroforestry for Indigenous communities. RIRDC Publication No.: 03/109. Kingston, ACT: Rural Industries Research and Development Corporation.

Campbell, B.M., Clarke, J.M., \& Gumbo, D.J. (1991). Traditional agroforestry practices in Zimbabwe. Agroforestry Systems, 14(2), 99-111.

Chase, A.K. (1989). Domestication and domiculture in northern Australia: a social perspective. In D.R. Harris \& G.C. Hillman (Eds.), Foraging and farming: the evolution of plant exploitation (pp. 42-54). Oxon: Routledge.

Clarke, W.C., \& Thaman, R.R. (1997). Incremental agroforestry: enriching Pacific landscapes. The Contemporary Pacific, 9(1), 121-148. 
Commonwealth of Australia. (2004). Opportunities and barriers for greater indigenous involvement in Australia's forestry industry: A scoping report addressing Indigenous involvement in the forestry and associated sectors for the National Indigenous Forestry Strategy Steering Committee. Report prepared by BDO Consulting (SA) Pty Ltd for the Department of Agriculture, Fisheries and Forestry, Aboriginal and Torres Strait Islander Services.

Cosgrove, R. (1996). Origin and development of Australian Aboriginal tropical rainforest culture: a reconsideration. Antiquity, 70(270), 900-912.

Cousins, S.R., \& Witkowski, E.T.F. (2015). Indigenous Plants: Key Role Players in Community Horticulture Initiatives. Human Ecology Review, 21(1), 59-85.

Courtenay, K. (2009). Practical principles. Remote Indigenous Gardens Network. Retrieved from http:// www.remoteindigenousgardens.net/useful-resources/practical-principals-by-kim-courtenay/.

Cunningham, A., Garnett, S., \& Gorman, J. (2009a). Policy lessons from practice: Australian bush products for commercial markets. GeoJournal, 74, 429-440. doi: 10.1007/s10708-008-9208-y.

Cunningham, A., Garnett, S., Gorman, J., Courtenay, K., \& Boehme, D. (2009b). Eco-Enterprises and Terminalia ferdinandiana: 'Best Laid Plans' and Australian policy lessons. Economic Botany, 63, 16-28. doi: 10.1007/s12231-008-9055-2.

Denham, T., Donohue, M., \& Booth, S. (2009). Horticultural experimentation in northern Australia reconsidered. Antiquity, 83, 634-648.

Edwards, G.P., \& Allan, G.E. (Eds.). (2009). Desert Fire: fire and regional land management in the arid landscapes of Australia. DKCRC Report 37. Alice Springs, NT: Ninti One Ltd.

Eyssartier, C., Ladio, A.H., \& Lozada, M. (2011). Traditional horticultural knowledge change in a rural population of the Patagonian steppe. Journal of Arid Environments, 75, 78-86.

Fawcett, A. (2011). Submission in response to the National Food Plan Issues Paper. Sydney, NSW: Remote Indigenous Gardens Network. Retrieved from http://www.remoteindigenousgardens.net/ wp-content/uploads/Anthea-Fawcett-RIG-Network-Submission-NFP-Issues-Paper.pdf

Gammage, B. (2011). The Biggest Estate on Earth: How Aborigines Made Australia. Sydney, NSW: Allen \& Unwin.

Ganz, D.J., \& Durst, P.B. (2003). Assisted Natural Regeneration: An overview. In P. Dugan, P. Durst, D. Ganz, and P. McKenzie (Eds.), Advancing assisted natural regeneration (ANR) in Asia and the Pacific (RAP Publication 2003/19). Bangkok: FAO Regional Office for Asia and the Pacific. Retrieved from http://ftp.fao.org/docrep/fao/004/ad466e/ad466e00.pdf

Gray, M., Hunter, B., \& Lohoar, S. (2012). Increasing Indigenous employment rates. Issues Paper; Closing the Gap Clearinghouse; No. 3. Canberra, ACT: Australian Institute of Health and Welfare \& Australian Institute of Family Studies. Retrieved from http://www.aihw.gov.au/uploadedFiles/ ClosingTheGap/Content/Publications/2012/ctg-ip03.pdf

Harris, D.R., \& Hillman, G.C. (1989). Foraging and farming: the evolution of plant exploitation. Oxon: Routledge.

Hill, R., Pert, P.L., Davies, J., Robinson, C.J., Walsh, F., \& Falco-Mammone, F. (2013). Indigenous Land Management in Australia. Extent, scope, diversity, barriers and success factors. Cairns, QLD: CSIRO Ecosystem Sciences.

Hynes, R.A., \& Chase A.K. (1982). Plants, sites and domiculture: Aboriginal influence upon plant communities in Cape York Peninsula. Archaeology in Oceania, 17(1), 38-50.

Joshi, L., Wijaya, K., Sirait, M., \& Mulyoutami, E. (2004). Indigenous systems and ecological knowledge among Dayak people in Kutai Barat, East Kalimantan - a preliminary report. ICRAF Southeast Asia Working Paper, No. 2004_3. Bogor: World Agroforestry Centre. Retrieved from http://www. worldagroforestry.org/downloads/Publications/PDFS/wp04193.pdf 
Keefe, K., Alavalapati, J.A.A., \& Pinheiro, C. (2012). Is enrichment planting worth its costs? A financial cost-benefit analysis. Forest Policy and Economics, 23, 10-16.

Ladio, A.H., \& Lozada, M. (2009). Human ecology, ethnobotany and traditional practices in rural populations inhabiting the Monte region: Resilience and ecological knowledge. Journal of Arid Environments, 73, 222-227.

Lee, L.S. (2012). Horticultural development of bush food plants and rights of Indigenous people as traditional custodians - the Australian Bush Tomato (Solanum centrale) example: a review. The Rangeland Journal, 34(4), 359-373.

Martini, E., Roshetko, J.M., van Noordwijk, M., Rahmanulloh, A., Mulyoutami, E., Joshi, L., \& Budidarsono, S. (2012). Sugar palm (Arenga pinnata (Wurmb) Merr.) for livelihoods and biodiversity conservation in the orangutan habitat of Batang Toru, North Sumatra, Indonesia: mixed prospects for domestication. Agroforestry Systems, 86(3), 401-407.

Merne Altyerre-ipenhe Reference Group, Douglas, J. \& Walsh, F. (2011). Aboriginal People, Bush Foods Knowledge and Products from Central Australia: Ethical Guidelines for Commercial Bush Food Research, Industry and Enterprises. DKCRC Report 71. Alice Springs, NT: Ninti One Ltd.

National Institute of Complementary Medicine. (2009). Researchers of Indigenous Medicine: National Forum Report. Brisbane, QLD: National Institute of Complementary Medicine.

Ninti One Ltd. (2015). Conversations, cups of tea, heat and dirt - A report on the Community Engagement and Plant Specimen Collection activities for the CRC-REP Plant Business Project. Alice Springs, NT: Ninti One Ltd.

Oelbermann, M., Voroney, R.P., \& Gordon, A.M. (2004). Carbon sequestration in tropical and temperate agroforestry systems: a review with examples from Costa Rica and southern Canada. Agriculture, Ecosystems and Environment, 104, 359-377.

Productivity Commission (2015). National Indigenous Reform Agreement, Performance Assessment, 2013-14. Canberra. Retrieved from http://www.pc.gov.au/research/supporting/indigenous-reformassessment/indigenous-reform-assessment.pdf.

Reij, C. (2010). Natural resource management in sub-Saharan Africa: successes, challenges and future directions. IFAD Report. Rome: International Fund for Agricultural Development.

Rural Industries Research and Development Corporation (RIRDC). (2014). Agricultural Competitiveness White Paper Submission IP288. Retrieved from http://agwhitepaper.agriculture.gov.au/ supporting-information/published-submissions-issue-paper.

Rola-Rubzen, M.F., Gibbs J., Gabunada, F., Altangerel, D., Fung, L., Rubzen, B., \& Carter, A. (2011). Growing businesses in the desert: Case studies of Australian desert micro, small and medium enterprises, DKCRC Report 74. Alice Springs, NT: Ninti One Ltd.

Schulze, P.C., Leighton, M., \& Peart, D.R. (1994). Enrichment planting in selectively logged rain forest: A combined ecological and economic analysis. Ecological Applications, 4(3), 581-592.

Suarez, A., Williams-Linera, G., Trejo, C. Valdez-Hernandez, J.I., Cetina-Alcala, V.M., \& Vibrans, H. (2012). Local knowledge helps select species for forest restoration in a tropical dry forest of central Veracruz, Mexico. Agroforestry Systems, 85(1), 35-55.

Takimoto, A., Nair, P.K.R., \& Nair, V.D. (2008). Carbon stock and sequestration potential of traditional and improved agroforestry systems in the West African Sahel. Agriculture, Ecosystems and Environment, 125, 159-166.

Torres, P. (2010). Can bush tucker provide meaningful lives and a path for Aboriginal people into the modern economy? In B. Collins. (Ed.), Barrgana Lecture. Broome, WA: Australian Broadcasting Corporation. Retrieved from www.abc.net.au/local/photos/2010/07/26/2964154. htm?site=kimberley. 
Walsh, F., Dobson, P.V., \& Douglas, J. (2013). Anpernirrentye: a Framework for Enhanced Application of Indigenous Ecological Knowledge in Natural Resource Management. Ecology and Society, 18(3), 18. doi: 10.5751/ES-05501-180318.

Walsh, F., \& Douglas, J. (2011). No bush foods without people: the essential human dimension to the sustainability of trade in native plant products from desert Australia. The Rangeland Journal, 33, 395-416. doi: 10.1071/RJ11028.

Whitehead, P.J., Purdon, P., Cooke, P.M., Russell-Smith, J., \& Sutton, S. (2009).The West Arnhem Land Fire Abatement (WALFA) project: The institutional environment and its implications. In J. RussellSmith, P. Whitehead \& P. Cooke (Eds.), Culture, Ecology and Economy of Fire Management in North Australian Savannas: Rekindling the Wurrk Tradition. Melbourne, VIC: CSIRO Publishing.

Yen, D.E. (1989). The domestication of environment. In D.R. Harris \& G.C. Hillman (Eds.), Foraging and farming: the evolution of plant exploitation (pp. 55-74). Oxon: Routledge. 